Portland State University

PDXScholar

1994

\title{
AIDS-Preventative Behaviors and the Psychological Costs of Behavior Change
}

Howard Balshem

Portland State University

Follow this and additional works at: https://pdxscholar.library.pdx.edu/open_access_etds

Part of the Psychology Commons

Let us know how access to this document benefits you.

\section{Recommended Citation}

Balshem, Howard, "AIDS-Preventative Behaviors and the Psychological Costs of Behavior Change" (1994). Dissertations and Theses. Paper 4705.

https://doi.org/10.15760/etd.6589

This Thesis is brought to you for free and open access. It has been accepted for inclusion in Dissertations and Theses by an authorized administrator of PDXScholar. Please contact us if we can make this document more accessible: pdxscholar@pdx.edu. 


\section{THESIS APPROVAL}

The abstract and thesis of Howard Balshem for the Master of Science in Psychology were presented August 5, 1994 and accepted by the thesis committee and the department.

COMMITTEE APPROVALS:

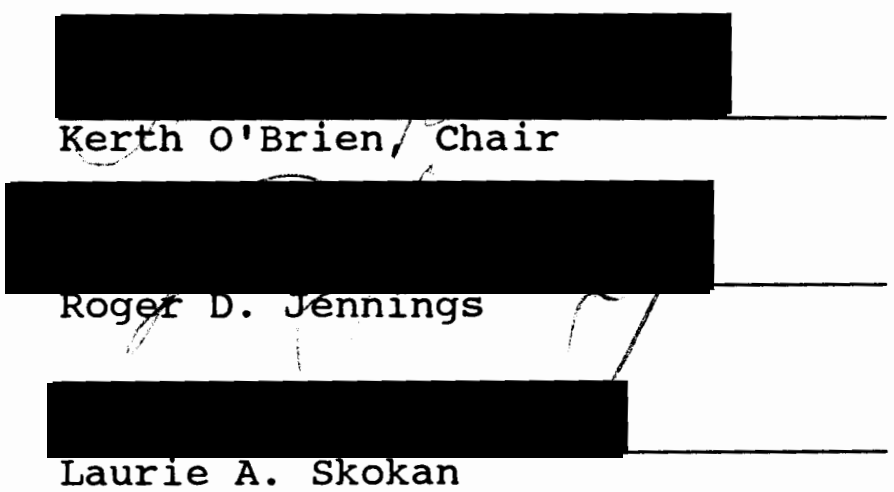

DEPARTMENTAL APPROVAL:

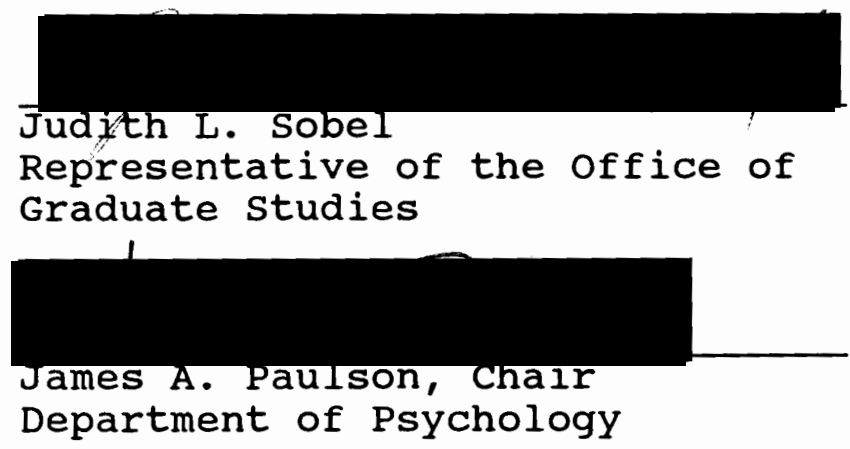

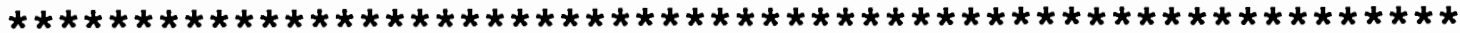
ACCEPTED FOR PORTLAND STATE UNIVERSITY BY THE LIBRARY on

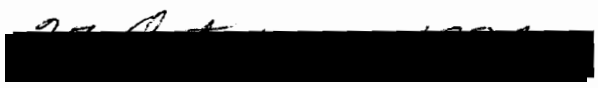


ABSTRACT

An abstract of the thesis of Howard Balshem for the Master of Science in Psychology presented August 5, 1994

Title: AIDS-Preventive Behaviors and the Psychological Costs of Behavior Change.

This study examined the effects of behavior change on psychological health among gay and bisexual men of Portland, oregon who were at risk for contracting AIDS. Cross-sectional self-reports of personal experiences were obtained in Summer, 1991. Sexual behaviors were used as predictors of self-efficacy, depression, anxiety, and subjective well-being. Adopting safer sexual behaviors was psychologically more costly than continuing to engage in high risk behaviors, or long-term adherence to safer behaviors. Behaviors amenable to short-term change differed from those conducive to long-term maintenance. Behavior change was also found to have a beneficial effect on self-efficacy. 
These findings suggest that behavior change, traditionally considered as the endpoint of a process, might more appropriately be considered as an interim stage influenced by earlier, and having an influence on later, psychological health. By integrating models of behavior change from research on alcohol and drug use, smoking, and weight control, researchers studying AIDS-related behavior might better understand the place of behavior change in the process of change, relapse, and maintenance. 
AIDS-PREVENTIVE BEHAVIORS AND THE PSYCHOLOGICAL COSTS OF BEHAVIOR CHANGE

by

HOWARD BALSHEM

A thesis submitted in partial fulfillment of the requirements for the degree of

\author{
MASTER OF SCIENCE \\ in
}

PSYCHOLOGY

Portland state University

1994 
(c) Howard Balshem

1994

All Rights Reserved 


\section{ACKNOWLEDGEMENTS}

I would like to thank my graduate committee, Kerth o'Brien, chair of the committee, Roger Jennings and Laurie skokan, for their support and encouragement, for their valuable input, and for their patience in what turned out to be a much longer process than I certainly had anticipated. The suggestions offered and revisions requested by my committee not only contributed to a much better thesis, but also helped in clarifying my own thinking on my subject.

I would like to especially acknowledge the support of Kerth o'Brien who generously allowed me use of data from the Portland Men's Study and provided encouragement to me from the conception of my project. Without her support and guidance this thesis would not have been possible. She was always understanding of my need to balance the demands of my academic life with the responsibilities of my work and family life.

I would also like to thank the faculty of the Department of Psychology at Portland State University. The graduate program helped provide me with both the intellectual and practical skills necessary to complete this thesis, and also for the demands of a successful 
career in applied research.

I would like to acknowledge the important role played by the cascade AIDS Project in encouraging community support for and participation in the Portland Men's study.

Finally and foremost, I would like to acknowledge the loving support of my wife, Martha Balshem, and my children, Rebecca and steven for enduring without complaint the many hours and weekends apart that this work has required. It was Martha who knew, when I did not, that I could complete not only this thesis but my graduate program. Without her encouragement and unwavering confidence in me none of this would have been possible. 
AIDS-Preventive Behaviors and the Psychological costs of Behavior Change

The set of symptoms which was later to be named Acquired Immune Deficiency syndrome (AIDS) was first recognized in the U.S. in 1981. Since that time over 360,000 people have been diagnosed with AIDS and over 220,000 have died from one or another of the associated opportunistic infections in the U.S. alone. It is estimated that there are currently over one miliion people infected by the Human Immunodeficiency Virus (HIV) in the U.S. (Centers for Disease control and Prevention, 1994).

Homosexual men were the first major group in the U.S. to become infected with HIV (Adib \& Ostrow, 1991), and still constitute one of the sub-populations with the highest prevalence of HIV infection and AIDS (Adib \& Ostrow, 1991; Centers for Disease Control and Prevention, 1993; Kelly \& Murphy, 1992). Although initial incidence rates among gay men were quite high, significant declines in infection rates have been brought about, largely through the educational efforts of the gay community itself (Adib \& Ostrow, 1991; Martin, 1987; McKusick, Coates, Morin, Pollack, \& Hoff, 
1990). The decline in the incidence of AIDS infection in the gay community was brought about by widespread changes in gay men's sexual behaviors. A number of studies have found significant declines in rates of unprotected anal intercourse among gay men (Becker \& Joseph, 1988; Mckusick, Coates, Morin, Pollack, \& Hoff, 1990).

Nevertheless, adoption of safer sexual practices among gay men has not been universal. Ten percent of the men participating in the San Francisco Men's Health study reported maintaining high risk sexual activity between 1984 and 1988 (Ekstrand \& Coates, 1990), while $6 \%$ of the men participating in the Multicenter AIDS Cohort study's coping and change study (MACS/CCS) reported maintaining high risk behaviors over a oneyear study period (Adib, Joseph, Ostrow, \& James, 1991). In addition, there is growing evidence that some men who had initially adopted safer sexual behaviors are again engaging in riskier behaviors (Kelly \& Murphy, 1992). Ekstrand and Coates, for instance, assessed risk behaviors of 686 gay and bisexual men over the period July 1984 to July 1988 . Subjects were considered high risk for a given one year 
period if they engaged in any unprotected anal intercourse in that year. Otherwise, they were considered low risk for that year. Defining relapse as a change from low risk behavior in one year to high risk behavior in any subsequent year, Ekstrand and Coates found that $16 \%$ of their subjects had reported relapsing to unprotected insertive anal sex while $12 \%$ had reported relapsing to unprotected receptive anal sex.

Similarly, Adib, Joseph, Ostrow, and James (1991) defined four categories of increasingly risky sexual behaviors: (1) not engaging in anal sex; (2) consistently using a condom during anal sex; (3) inconsistently using a condom during anal sex; and (4) never using a condom. subjects were interviewed three times in the course of the one year study about their sexual activity during the month prior to the interview, and $31 \%$ of the participants reported relapsing from safer to less safe sexual activity.

Because of the high HIV infection rate among homosexually active men, those who do engage in unprotected anal intercourse are at high risk for HIV infection. Although it is clear that work must 
continue in helping gay men to adopt safer sexual

behaviors, it is also clear that it is equally

important to find ways to enable them to maintain safer sexual behaviors once adopted (Adib \& Ostrow, 1991).

It is the psychological consequences of behavior change and the effects of those consequences on maintenance that were the focus of this study.

\section{Behavior Change as an Endpoint}

Traditionally, behavior change has been viewed as the final outcome of a linear process. This study viewed behavior change as an interim point in a cyclical process, and examined its independent effects on later outcomes --- in this study, psychological outcomes.

A number of theoretical perspectives have been tapped in the attempt to understand how to change AIDSrisk behaviors effectively, and each has met with some measure of success (Aspinwall, Kemeny, Taylor, Schneider, and Dudley, 1991; Catania, Kegeles, \& Coates, 1990; Fishbein, 1990; Fisher \& Fisher, 1992; Montgomery, Joseph, Becker, Ostrow, Kessler, \& Kirscht, 1989). None, however, can claim success that is 
unqualified.

The Health Belief Model (HBM) (Becker, 1974; Janz and Becker, 1984) suggests that health-related behaviors can be understood as arising from: (1) subjective perceptions of the risk of a particular health threat (susceptibility); (2) the perceived severity of the threat; (3) the perceived benefits of a particular behavioral adaptation to the health threat; and (4) the perceived costs of that particular behavioral adaptation. Montgomery, Joseph, Becker, Ostrow, Kessler, \& Kirscht (1989) found little support for the effectiveness of the HBM. Susceptibility, perceived benefits of behavior change, and barriers to change were of only minor importance. Only perceived severity consistently predicted the use of receptive anal intercourse. Aspinwall, Kemeny, Taylor, Schneider, and Dudley (1991) also found partial support for the Health Belief Model. Aspinwall et al. found that the HBM was effective in predicting health behaviors for specific subgroups of gay men. For HIV seropositive but not seronegative men, response efficacy was a significant predictor. Similarly for men without primary partners, but not for those with 
primary partners, perceived risk was a significant predictor of the number of sexual partners. As pointed out by salt, Boyle, \& Ives (1990), the Health Belief Model can not easily account for the many situational and social factors which are important influences on sexual behaviors. Situational factors such as sexual arousal or the use of intoxicants may interfere with the intentionality of behavioral action posited by the HBM, as may the socially complex nature of AIDS-related behaviors. The individual is confronted with an array of potential behavioral responses from celibacy to anal sex only with a condom from which to choose, none of which, besides celibacy, offers any certainty of protection. In addition, the individual does not make this choice alone, but must negotiate the choice with a sexual partner or partners. All of these factors act to weaken the applicability of the HBM.

The Theory of Reasoned Action (Ajzen \& Fishbein, 1980; Fishbein \& Ajzen, 1975) suggests that an individual's behavior is determined by behavioral intentions, which are in turn dependent upon the relative importance of attitudes towards the behavior and perceptions of social norms regarding the 
particular behavior. Although there is some evidence for the efficacy of this model (Fishbein, 1990) in predicting the behavioral intentions of college students to use condoms, Fishbein's study does not present any evidence for the relationship between behavioral intention and the actual use of condoms. In addition, its focus on college students limits the generalizability of the results.

An interesting extension of the Theory of Reasoned Action has recently been suggested by Fisher \& Fisher (1992). In their Information-Motivation-Behavioral (IMB) skills model, the Theory of Reasoned Action is used as the basis for their motivational construct. According to the IMB model, information and motivation act through behavioral skills to bring about behavioral change. Again, while particular aspects of the model are supported by their study, there are a number of notable gaps. In their study of gay men, information and motivation were related to behavioral skills and motivation was related to AIDS-preventive behavior at time one. However, the predicted relationship between behavioral skills and AIDS-preventive behaviors was not found. The model was fully verified only on a sample 
of university students.

Finally, the AIDS Risk Reduction Model (ARRM) (Catania, Kegeles, \& Coates, 1990) attempts to integrate elements of the Health Belief Model and the Theory of Reasoned Action into a comprehensive framework for conceptualizing the process of changing sexual behaviors related to HIV transmission. In addition, the ARRM expands on these models by the integration of self-efficacy theory into the model. Self-efficacy has to do with the perception that one is capable of performing actions or exerting self-control that will lead to a desired outcome, and is a central element of Social Learning Theory (Bandura, 1977)

The ARRM suggests a three stage process by which people adopt behaviors to reduce the risk of contracting AIDS. In the first stage, labeling, the individual recognizes specific behaviors as high risk for contracting AIDS. In stage two, the individual makes a commitment to reduce high risk behaviors. In stage three, enactment, he seeks strategies and takes action to reduce high risk behaviors. As such it borrows from models of behavior change related to smoking behaviors discussed below, in particular, to 
cycle of change models (Prochaska and Diclemente, 1983). The AIDS Risk Reduction Model is relatively new and there is little published evidence of its effectiveness. However, as a model of behavior change, it does not address the issue of maintenance. As such it shares with traditional models the conception of behavioral outcomes as endpoints.

\section{Behavior Change as Process}

While much of the research on AIDS has focused on ways to change people's behaviors in the direction of safer sexual practices (Catania et al., 1991; Fishbein, 1990; Kaemingk \& Bootzin, 1990; Kelly \& st. Lawrence, 1990), recently studies have become concerned with the problem of maintenance of these behaviors. This concern arises with growing evidence that many men who have adopted safer sexual behaviors relapse to less safe behaviors. Ekstrand \& Coates (1990) in the study described above, for example, found a higher percentage of gay men who had relapsed to high risk behaviors than had maintained high risk behaviors over the 4 year study period. Despite the growing interest in maintenance, however, AIDS researchers have adhered to 
a model which views behavior change as a successful final outcome. To find models which view behavior change as an interim step in a process of change, maintenance, and relapse, we must move on to the literature on addictive behaviors.

Although maintenance and relapse have only recently become a focus of AIDS research, there is a rich literature on relapse related to other areas of behavior change such as smoking cessation, dieting, and drug and alcohol abuse. Few AIDS researchers have made use of the literature on addictive behaviors (but see Kelly, st. Lawrence, \& Brasfield, 1991), although some have recognized the need for such synthesis (Mckusick, Coates, Morin, Pollack, \& Hoff, 1990; Salt, Boyle, \& Ives, 1990).

Marlatt (1985) and Peele (1985) provide excellent overviews of traditional models of addiction. Early moral models saw the addict as someone lacking in the "'moral fiber' to resist temptation" (Marlatt, 1985). This moral model was succeeded by the disease model of addiction which views addictive behaviors as resulting from inherent physical dependencies (Marlatt, 1985). The view of alcoholism as disease is exemplary of this 
approach. The attractiveness of the disease model is that it removes the onus of moral blame from the addict. If alcohol dependency is by nature based on biological factors outside of the control of the addict, then the alcoholic is no more to blame for the outward manifestations of his illness than a diabetic is to be blamed for his (Marlatt, 1985). Marlatt, however, considers the disease model to be potentially counterproductive under conditions of relapse, since the individual may view the lapse as evidence of the uncontrollable nature of the illness and acquiesce to the addictive behavior. Marlatt (1985) also criticizes the disease model for on the one hand claiming that addictive behaviors are outside of the control of the individual, while on the other hand insisting that the only cure for the addiction is abstinence or total control of the behavior by the addict.

The enlightenment model is similar to the moral model in that it places the blame for the origin of the problem on the individual. However, unlike the moral model, which places the onus for resolving the addiction on the individual, the enlightenment model claims that the individual cannot resolve the problem 
in the absence of spiritual and community support. The philosophy of Alcoholics Anonymous is exemplary of the enlightenment model (Brickman, Rabinowitz, Karuza, Coates, Cohn, \& Kidder, 1982; Marlatt, 1985).

Peele (1985) criticizes all of these models for ignoring the importance of social and environmental factors in the development of dependent behaviors. While not denying the role of personal responsibility and biological determinants of addiction, Peele argues for a more complex psychosocial model of addiction which views cravings and compulsions as arising not simply from personal failure or biological determinacy, but also from contextual and social cues.

More recent models of drug, alcohol, and smoking use have attempted to redefine our understanding of these behaviors. Rather than characterizing addiction as an aberrant behavior, these models focus on the commonalities of all habitual behaviors. And rather than considering abstinence from addictive behaviors as having some kind of unique property, these models focus on the commonalities in the processes involved in changing to and maintaining any new behaviors, habitual or not. 
Marlatt, in his Relapse Prevention model, (Marlatt \& Gordon, 1985) for example, describes addictive behaviors as "any compulsive habit pattern in which the individual seeks a state of immediate gratification [italics in original]," (Marlatt, 1985, p. 4) and as "overlearned habits [italics in original] that can be analyzed and modified in the same manner as other habits" (p. 9). Peele (1985) also proposes a model of "addictive" behavior which is applicable to a wide variety of harmful behaviors including self-destructive running, compulsive group involvement, and compulsive eating.

In addition, these more recent models view addiction and relapse as processes of behavioral adaptation and change rather than as static, dead-end states. Marlatt's Relapse Prevention (RP) model (Marlatt and Gordon, 1985) describes a process in which the maintenance of an abstinent behavior is supported by enhanced feelings of self-efficacy so long as abstinence is maintained. However, this sense of selfefficacy can be challenged by failure to maintain abstinence in high-risk situations. These high-risk situations can arise through either intrapersonal 
determinants, such as negative emotional states, or interpersonal determinants such as social pressure or conflict. According to the RP model, individuals who successfully cope with a high risk situation should achieve an enhanced sense of self-mastery and selfefficacy. The RP model also emphasizes the importance of recognizing that factors influential in bringing about behavior change may be very different from those which are influential in maintenance of adopted behaviors.

Prochaska and Diclemente (1983) also describe addiction and relapse as part of an overall cycle of behavior change. In their cycle of change model, the individual passes through four stages: precontemplation, contemplation, action, and maintenance. In the precontemplation stage individuals have not yet even considered changing their behavior. In the contemplation stage the individuals are considering, but not yet committed to, changing their behavior. Once a commitment to change is made the individual enters the action stage and if successful passes into the maintenance stage. It is important to recognize that this model describes a cyclical rather 
than a linear model of behavior change. Rather than being a static end to the model, the maintenance stage is a dynamic and active stage from which individuals can return to earlier contemplative or precontemplative stages.

\section{The current study}

Although it has been within the domain of what have traditionally been considered addictive behaviors that the relapse prevention and cycle of change models have been applied, it is as general models of behavioral change that they are relevant to the study of AIDS-related behavior. The two elements of these models focused on in this study were 1) the concept of behavior change as a cyclical process, and 2) the role of self-efficacy in that process.

While behavior change, maintenance, and relapse are important components of models of habit change drawn from the addiction literature, these models stop short of looking specifically at the psychological effects of behavior change and whether those psychological outcomes influence maintenance and relapse. A central goal of this study has been to 
provide evidence that behavior change itself has psychological consequences which may influence later behaviors such as relapse and maintenance.

\section{The Cyclical Nature of Behavior Change}

If behavior change is in fact a cyclical process, then the adoption of safer sexual behaviors is not the end to that process. However, this is exactly how most studies have treated these behaviors. The adoption of safer sexual behaviors has been considered as an outcome that is related to predictors such as selfefficacy (Aspinwall, Kemeny, Taylor, Schneider, \& Dudley, 1991; McKusick, Coates, Morin, Pollack, \& Hoff, 1990) and social support (Catania et al., 1991; Siegel, Mesagno, Chen, \& Christ, 1989).

This is not to say that psychological outcomes have been ignored. A number of studies have examined the psychological costs paid by those affected by the AIDS epidemic. These studies have examined the psychological impact of serostatus itself (Kessler et al., 1988); and of loss and bereavement (Martin, 1987; Martin, Dean, Garcia, \& Hall, 1989); as well as the overall psychological impact of the epidemic on gay men 
at risk for AIDS (Joseph, Caumartin, et al., 1990). Few studies, however, have examined the psychological costs of changing one's behaviors, although the need for further studies evaluating such costs has been recognized (Joseph, Kessler, et al., 1989; Kelly \& Murphy, 1992). One goal of this study was to examine the psychological correlates of some of the behavioral changes made by gay men to cope with the threat of AIDS, as well as some of the factors which can enhance adherence to safer sexual behaviors. An understanding of these associations will better enable us to apprehend the reciprocal nature of the relationship between behavior change and psychological health, and to see both as part of an ongoing process in which each influences the other.

The Role of Self-Efficacy in Behavior Change

Relapse to unsafe sexual behaviors has been found to be related to social support (Adib, Joseph, Ostrow, \& James, 1991; Ekstrand \& Coates, 1990); to assertiveness in negotiating safer sex (Adib, Joseph, Ostrow, \& James, 1991); to the reinforcement value of previous high-risk behaviors, the use of intoxicants 
during sexual activity, and age (Kelly, st. Lawrence, \& Brasfield, 1991); and most consistently to an individual's number of sexual partners (Adib, Joseph, Ostrow, \& James, 1991; Ekstrand \& Coates, 1990; Kelly, st. Lawrence, \& Brasfield, 1991).

similarly, research in areas such as drug and alcohol abuse, smoking, and overeating has found relapse to be related to social support (Brownell et al., 1986) and coping skills (Grilo, Shiffman, \& Wing, 1989; Hall, Havasy, \& Wasserman, 1991; Prochaska, Crimi, Lapsanski, Martel, \& Reid, 1982). However, this research also suggests that relapse is strongly related to self-efficacy (Prochaska, Crimi, Lapsanski, Martel, \& Reid, 1982).

Rather than attempting to arbitrate among the many potential influences in successful behavior change and maintenance, this study, as its second goal, focused on self-efficacy. Self-efficacy is an element common to nearly all theories of behavior change, and has been found to have an important effect on wide range of health related behaviors (Bandura, 1986; Diclemente, 1986; O'Leary, 1985) including smoking (Velicer, Diclemente, Rossi, \& Prochaska, 1990; Yates \& Thain, 
1985), alcohol use (Rollnick \& Heather, 1982), and dieting and eating disorders (Sternberg, 1985, cited in O'Leary, 1985). Siegel, Mesagno, Chen, and Christ (1989) found perceived difficulty in modifying sexual behavior to be a significant discriminator between homosexual males practicing riskier and safer sex. Self-efficacy was also found to be an important predictor of sexual risk activity by McKusick, Coates, Morin, Pollack and Hoff (1990). This study attempted to further confirm the important role of self-efficacy by assessing the effect on self-efficacy of adherence to safer sexual behaviors.

Factors Influencing Psychological outcomes and Selfefficacy

Two aspects of behavior change examined were:

the type of behavior change adopted; and (2) the time at which the behavior change was adopted.

Influence of Type of Behavior Change

Joseph, Kessler, et al. (1989), while finding that there are costs associated with behavior change, did not assess the differential impact on psychological 
health of specific behavior changes. It seems likely, however, that men who have adopted substitute behaviors such as masturbation may be less adversely affected than men who have chosen to remain celibate. It is important to know, especially in the critical period during which new behavioral patterns are developing, whether some behaviors are more likely to lead to long term success than others.

\section{Influence of Time of Behavior Change}

It is also likely, however, that the type of behavioral adaptations which are successful in the long term differ from those which may contribute to success in the short term. Behaviors which enable men to successfully change from previous behaviors may differ from behaviors which are supportive of long-term maintenance. Celibacy, for example may be a successful strategy for changing to safer sexual behaviors, but a poor strategy for long-term maintenance of safer sexual behaviors. Masturbation, on the other hand, may be a poor strategy for behavior change, but a good strategy for maintenance. This study, therefore, also examined whether the behaviors which are least costly in 
bringing about behavior change (i.e., those with the least harmful psychological outcomes) differ from those which are least costly in enabling long-term maintenance.

As there are likely to be, for some men, considerable psychological costs to changing what had become habitual and favored patterns of sexual interaction (Joseph, Emmons et al., 1984), it also seems likely that the burdens of behavior change may be most severe in the period immediately following the adoption of the new behavioral pattern. This study also assessed differences in psychological health for men who have only recently adopted safer sexual practices as compared to those who have either not adopted those behaviors or those who have maintained those behaviors for one year or more.

\section{Hypotheses}

1. Levels of anxiety and depression will be higher, and levels of general well-being will be lower for those who have only recently adopted safer sexual behaviors (no unprotected anal intercourse in past 30 days) than for either those who have not adopted safer 
sexual behaviors or for those who have adhered to safer behaviors for 1 year or longer. This hypothesis compares the psychological health of non-adherents and long-term adherents with that of the short-term adherents. It suggests that the immediate psychological effects of behavioral change are more harmful than either maintaining previous behaviors or long-term maintenance of new behaviors.

2. Levels of depression and anxiety will be lower and levels of well-being higher for those who have adhered to safer sexual behaviors (no unprotected anal sexual intercourse) for one year or longer than for those who are still engaging in unprotected anal intercourse. This hypothesis, in contrast with Hypothesis 1, suggests that although the maintenance of previous behaviors or the long-term maintenance of new behaviors is psychologically less harmful than the immediate effects of behavioral change, the maintenance of riskier sexual behaviors is nonetheless psychologically more costly than the long-term maintenance of new, even if less preferred, safer sexual behaviors. 
3. Self-efficacy will be higher for those who have adopted safer sexual behaviors than for those who have not.

4. Self-efficacy will be higher for those who have adhered to safer sexual behaviors for more than one year than for those who have only recently adopted safer sexual behaviors.

5. It is possible that the psychological costs of adherence may differ depending on the particular behavior adopted. Those men who, for example, are completely celibate may suffer more psychological costs than those who find surrogate behaviors for high risk sexual activities. Hypothesis 5, therefore, states that among those men who recently adopt safer sexual behaviors, the psychological costs of adherence will differ depending on the type of behavior adopted. The behaviors examined: celibacy, masturbation with or without a partner, oral or anal sex with a condom, and oral sex without a condom are described in Appendix A. 6. The same behaviors will have different psychological effects on long-term adherents than on recent adherents. As an example, while celibacy may 
prove to be a successful adaptation in the short run with positive psychological correlates, it may prove to be psychologically unsuccessful as a long-term maintenance strategy. This may be true even if longterm celibacy is psychologically more successful than maintaining unsafe sexual behaviors as is proposed in Hypothesis 2 .

It should be noted that while this study suggests a causal model for the relationship between behavioral change and psychological outcomes, the data are crosssectional and cannot provide any conclusive evidence of causality. With this caveat in mind, I will describe this study using language that reflects a conceptual model which proposes causal relationships.

\section{Method}

Subjects

This study was based on a secondary analysis of data collected by O'Brien (1992)". Self-administered questionnaires were completed in 1991 by 758 gay and bisexual men from the Portland, oregon metropolitan

'The Portland Men's Study was funded by a grant from the National Institute of Mental Health (1R03MH45640-01A1), Kerth O'Brien, Principal Investigator. 
area recruited through contacts with local community organizations, health services, public events of interest to the gay community, and exit intercepts at bars and clubs. The response rate was $35 \%$. Men who reported being in a monogamous relationship of longer than six months in which both the respondent and his partner were seronegative were dropped from this analysis. The remaining 697 men were those considered to be at risk for contracting AIDS.

\section{Independent Variables}

In this study behaviors traditionally considered as outcome variables were treated as independent variables influencing psychological outcomes. These variables were operationalized as frequencies of or engagement in specific sexual behaviors. Information on sexual practices for two time periods were collected.

First, respondents were asked about the frequency of several different forms of sexual activity for the period 30 days prior to completion of the questionnaire. These activities were insertive and receptive oral and anal sex without ejaculation and 
without a condom; insertive and receptive oral and anal sex with ejaculation and without a condom; insertive and receptive oral and anal sex with a condom; masturbation by a partner; masturbation of a partner; self masturbation while with a partner; and self masturbation while by oneself. Men who indicated they were in a primary relationship reported their activities with that partner. In addition, all men reported their sexual activities with partners other than a primary partner.

second, respondents were also asked whether they had had anal sex without a condom in the past year whether in a primary relationship or not.

These data were used to establish three different time frames for adherence to safer sexual behaviors. The currently non-adherent men were those who indicated that they had anal sex without a condom in the past thirty days. The newly adherent men were those who indicated that they had anal sex without a condom in the past year, but not in the past 30 days. Finally the long-term adherent men were those who indicated that they had not had anal sex without a condom for the past year. 
Interpersonal and Social Variables

Because of the demonstrated influence of interpersonal and social variables on AIDS-preventive behavioral change (O'Brien, 1992; Aspinwall, Kemeny, Taylor, Schneider, \& Dudley, 1991; McKusick, Coates, Morin, Pollack, \& Hoff, 1990), these variables were used as controls on the influence of behavior change on psychological outcomes. These controls included measures of social support, social conflict, and social influence. All three measures were assessed for their influence from a primary partner if the respondent was in a primary relationship, and from other people, particularly friends, in the respondent's social network.

\section{Self-Efficacy}

Self-efficacy in maintaining AIDS-preventive behaviors was assessed through self-reported measures of the respondent's social skills in negotiating safer sexual relationships.

\section{Psychological outcomes}

Three psychological outcome measures were used. 
Depression was measured by a subset of items from the Center for Epidemiologic Studies-Depression scale (CESD; Radloff, 1977); anxiety, by the anxiety scale of the Hopkins symptom Checklist (SCL-58; Derogatis, Lipman, Rickels, Uhlenhuth, \& Covi, 1974); and subjective wellbeing by a measure adapted by O'Brien (1988) from Veroff, Douvan, \& Kulka (1981) and including a measure of global life satisfaction adapted from Andrews and Withey (1976).

\section{Time Periods}

Although longitudinal data were not available, information on self-reported adherence to safer sexual behaviors was available for three different time frames. As discussed above, these periods were 1) not practicing safer sex at the time of the study; 2) adhering to safer sexual behaviors for less than one year, but longer than 30 days; and 3) adhering to safer sexual behaviors for 1 year or longer at the time of the study. 
operationalization of the Hypotheses

\section{Hypotheses 1 and 2}

Four broad questions were examined. The first asked how psychological health relates to behavior change. In particular it asked if recent behavior change adversely affects psychological health and whether psychological health improves with the maintenance of these newer behaviors. To examine these questions psychological health was regressed on orthogonally coded variables representing categories of adherence longevity, and orthogonal comparisons representing Hypotheses 1 and 2 were performed. If a significant relationship was found, additional analyses including the social and interpersonal variables were performed to confirm that the relationship of interest still held when these additional variables were included in the model.

In the first comparison, the health of short-term adherents was contrasted with both non-adherents and long-term adherents to assess whether the adoption of safer sex behaviors has a short-term negative impact on psychological health. In the second comparison, the 
psychological health of long-term adherents was contrasted with the health of non-adherents to assess whether psychological health improves with long term maintenance of safer sexual behaviors. Because the three adherence groups were of unequal size, orthogonal coding was employed which took into account the unequal cell sizes.

In the first comparison, in which group 2 (shortterm adherents) was contrasted with groups 1 and 3 (non-adherents and long-term adherents) coefficients for the comparison were $-n$ for groups 1 and 3 , and $n_{1}$ $+n_{3}$ for group 2. The resulting comparison:

$$
\left(n_{1}\right)\left(-n_{2}\right)+n_{2}\left(n_{1}+n_{3}\right)+n_{3}\left(-n_{2}\right)=0
$$

is, therefore, a valid contrast.

In the second comparison, group 3 (long-term adherents) was contrasted with group 1 (non-adherents). The coefficients for this comparison were $n_{3}$ for group 1 and $-n_{1}$ for group 3 with zero as the coefficient for group 2. The resulting comparison:

$$
\left(n_{1}\right)\left(n_{1}\right)+\left(n_{1}\right)(0)+\left(n_{1}\right)\left(-n_{1}\right)=0
$$

is also a valid comparison and orthogonal to the first comparison. Using orthogonal comparisons, tests of the b's from the resulting regression equation provided a 
direct test of the comparison it reflected (Pedhazur, 1982).

Hypotheses 3 and 4

The next question examined asked if self-efficacy is enhanced by the persistent adherence to safer sexual behaviors. Here an index of self-efficacy was regressed on orthogonally-coded variables of adherence longevity in a manner similar to that described above. First, the self-efficacy scores of all adherents was contrasted with that of non-adherents to assess whether self-efficacy is higher among those who have adopted safer sexual behaviors. Next, the self-efficacy scores of long-term adherents was contrasted with those of newly-adherent respondents to determine whether selfefficacy continues to be improved by the long-term adherence to these behaviors.

Hypothesis 5

A third question asked whether for those who have recently adopted safer sexual behaviors (short-term adherents), psychological health differs depending on the types of safer sexual behaviors adopted. Only 
short-term adherents were included in this analysis. A sexual behavior variable was effect-coded to classify these respondents by the types of safer sexual behaviors in which they engaged. Originally, groups consisted of: 1) those who engaged in oral sex without a condom; 2) those who engaged in anal or oral sex with a condom but not oral sex without a condom; 3) those who masturbated, but did not engage in oral sex without a condom, anal sex with a condom, or oral sex with a condom; and, 4) those respondents who were celibate (i.e. did not masturbate or engage in any other sexual activity).

Because of the small cell size for some of these categories, however, subjects were regrouped into two categories depending on whether they engaged in penetrating or non-penetrating safer sexual behaviors. Penetrating behaviors were oral sex with or without a condom and anal sex with a condom. Non-penetrating behaviors were celibacy and masturbation.

Psychological health was then regressed on this two category sexual behavior variable to assess whether adopting penetrating or non-penetrating behavior resulted in better psychological health among recent 
adherents to safer sexual behaviors. Again, when a significant relationship was found additional analyses including the social and interpersonal variables were performed to confirm that the relationship of interest still held when these additional variables were included in the model.

Hypothesis 6

The final question examined was whether the adoption of the same safer sexual behaviors differentially affects long- and short-term adherents. To examine this question both long-term and short-term adherents were included in the model. The previous analysis was supplemented by the inclusion of the adherence longevity index, and the interaction (multiplicative term) between longevity and behavior type was examined.

\section{Results}

Table 1 presents demographic and other background characteristics of the sample. Tables 2 and 3 present the means, standard deviations, and ns for depression, anxiety, subjective well-being, and self-efficacy for all adherence categories and behavior types. 
Table 1

Demographics $(n=697)$

Mean Age $\quad 35.8$

Variable

8

Race

White (non-Hispanic)

90.5

Hispanic

2.3

Black

1.7

American Indian/Alaskan Native

2.0

Asian, Asian-American

1.3

other

.9

Not ascertained

1.3

Education

Didn't complete high school

1.3

High school graduate

$9 \cdot 9$

Technical school

4.7

some college

37.2

College graduate

19.7

Some graduate work

26.5

Not ascertained

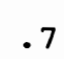

(table continues) 
Relationship status

Not in a primary relationship

58.2

In a primary relationship with a man

39.5

In a primary relationship with a man and a woman

In a primary relationship with a woman

1.3

Other

Sexual orientation

Gay

92.1

Bisexual

6.6

Not ascertained

1.3 
Table 2

Mean Scores on Psychological outcomes by Adherence and Behavior Category

\begin{tabular}{|c|c|c|c|c|c|c|c|c|c|}
\hline & \multicolumn{3}{|c|}{ Depression } & \multicolumn{3}{|c|}{ Anxiety } & \multicolumn{3}{|c|}{ Well-Being } \\
\hline & $M$ & $(S D)$ & $n$ & $M$ & $(S D)$ & $\mathbf{n}$ & $\mathbf{M}$ & (SD) & $\mathbf{n}$ \\
\hline Non-Adherent & 34.3 & $(20.6)$ & 177 & 18.0 & $(14.5)$ & 178 & 61.8 & $(23.9)$ & 179 \\
\hline Recent Adherent & 37.9 & $(23.0)$ & 109 & 18.7 & $(18.8)$ & 108 & 54.3 & $(24.6)$ & 109 \\
\hline Celibate & 45.3 & $(26.8)$ & 5 & 24.0 & $(15.2)$ & 5 & 59.6 & $(17.3)$ & 5 \\
\hline Masturbate & 47.0 & $(30.6)$ & 18 & 30.7 & $(27.2)$ & 18 & 44.7 & $(30.5)$ & 18 \\
\hline Condoms & 13.3 & $(5.4)$ & 4 & 16.3 & $(11.1)$ & 4 & 72.8 & $(18.7)$ & 4 \\
\hline No Condoms & 37.4 & $(20.8)$ & 76 & 16.3 & $(16.5)$ & 75 & 54.5 & $(24.0)$ & 76 \\
\hline Penetrator & 36.2 & $(20.9)$ & 80 & 16.3 & $(16.2)$ & 79 & 55.4 & $(23.5)$ & 80 \\
\hline Non-Penetrator & 46.7 & $(29.3)$ & 23 & 29.2 & $(24.9)$ & 23 & 48.0 & $(28.5)$ & 23 \\
\hline Long-term Adherent & 34.9 & $(21.6)$ & 354 & 16.5 & $(16.9)$ & 356 & 60.2 & $(23.6)$ & 356 \\
\hline Celibate & 51.9 & $(17.7)$ & 19 & 22.1 & $(23.6)$ & 19 & 39.8 & $(18.4)$ & 19 \\
\hline Masturbate & 37.3 & $(22.4)$ & 92 & 17.5 & $(18.7)$ & 92 & 58.3 & $(24.0)$ & 92 \\
\hline Condoms & 32.6 & $(18.6)$ & 18 & 12.1 & $(10.3)$ & 18 & 67.5 & $(25.8)$ & 18 \\
\hline No Condoms & 32.3 & $(21.2)$ & 204 & 15.4 & $(14.8)$ & 206 & 62.8 & $(22.5)$ & 206 \\
\hline Penetrator & 32.3 & $(21.0)$ & 222 & 15.1 & $(14.5)$ & 224 & 63.2 & $(22.7)$ & 224 \\
\hline Non-Penetrator & 39.8 & $(22.3)$ & 111 & 18.3 & $(19.6)$ & 111 & 55.1 & $(24.1)$ & 111 \\
\hline Penetrator & 33.3 & $(21.0)$ & 302 & 15.4 & $(14.9)$ & 303 & 61.2 & $(23.3)$ & 304 \\
\hline Non-Penetrator & 41.0 & $(23.7)$ & 134 & 20.2 & $(20.9)$ & 134 & 53.9 & $(25.0)$ & 134 \\
\hline Total Sample & 35.2 & $(21.5)$ & 651 & 17.3 & $(16.5)$ & 653 & 59.8 & (23.9) & 655 \\
\hline
\end{tabular}


Table 3

Meań Scores on self-efficacy

Non-Adherent

Recent Adherent

Iong-term Adherent

Total sarmple

\begin{tabular}{ccr}
\multicolumn{3}{c}{ Self-Efficacy } \\
$M$ & $(S D)$ & $\mathbf{n}$ \\
74.5 & $(16.6)$ & 176 \\
78.4 & $(14.2)$ & 107 \\
83.2 & $(14.3)$ & 347 \\
79.7 & $(15.9)$ & 641
\end{tabular}

76

641 
Hypotheses 1 and 2

To test Hypotheses 1 and 2 psychological health was regressed on a set of orthogonally coded variables. The first variable, testing Hypothesis 1 , contrasted recent adherents with long-term and non-adherents. The second variable, testing Hypothesis 2 , contrasted longterm adherents with non-adherents. Adherence was found to be related to subjective well-being but not to depression or anxiety (Table 4). As predicted by Hypothesis 1, subjective well-being was higher for long-term and non-adherents than for recent adherents $\left(R^{2}=.011, F_{(-, 61)}=3.526, p=.030\right)$. This relationship held even when the social support, influence, and conflict variables were included in the model. Although most of the variance in the model was accounted for by these social variables $\left(R^{2}=.166\right.$, $\left.F_{(3,593)}=39.684, p=.000\right)$ adherence still accounted for a significant if small amount of the variance in the model after controlling for the social variables $\left(R^{2}=.010, F_{(2,5 y)}=3.735, p=.024\right)$. However, no significant difference in levels of depression or anxiety was found either when adherence was included in the model alone or included in the model with the set 


\section{Table 4}

Mean Scores on Psychological Outcomes for Contrasts Comparing Recent Adherents with Long-Term and Non-Adherents (Hypothesis 1), and Non-Adherents with Long-Term Adherents (Hypothesis 2)

\begin{tabular}{|c|c|c|c|c|c|c|c|c|c|}
\hline & \multicolumn{3}{|c|}{ Depression } & \multicolumn{3}{|c|}{ Anxiety } & \multicolumn{3}{|c|}{ Well-Being } \\
\hline & $M$ & $(S D)$ & $n$ & $M$ & $(S D)$ & $n$ & $M$ & $(S D)$ & $n$ \\
\hline \multicolumn{10}{|l|}{ Hypothesis 1} \\
\hline Recent Adherent & 37.9 & $(23.0)$ & 109 & 18.7 & $(18.8)$ & 108 & 54.3 & $(24.6)$ & 109 \\
\hline Long-term/Non- & 34.7 & $(21.3)$ & 531 & 17.0 & $(16.1)$ & 534 & 60.7 & $(23.7)$ & 535 \\
\hline \multicolumn{10}{|l|}{ Adherent } \\
\hline & $b=.005$ & $t=1.42$ & $p=.158$ & $b=.003$ & $t=.963$ & $p=.336$ & $b=-.010$ & $t=-2.55$ & $p=.011$ \\
\hline \multicolumn{10}{|l|}{ Hypothesis 2} \\
\hline Non-Adherent & 34.3 & $(20.6)$ & 177 & 18.0 & $(14.5)$ & 178 & 61.8 & $(23.9)$ & 179 \\
\hline Long-term & 34.9 & $(21.6)$ & 354 & 16.5 & $(16.9)$ & 356 & 60.2 & $(23.6)$ & 356 \\
\hline & $b=.001$ & $t=.330$ & $p=.742$ & $b=-.003$ & $t=-.971$ & $p=.332$ & $b=-.003$ & $t=-.748$ & $p=.455$ \\
\hline
\end{tabular}


of social variables.

No support was found for Hypothesis 2. As shown in Table 4, no significant differences in mean scores for depression, anxiety, and subjective well-being were found between long-term adherents and non-adherents.

Hypotheses 3 and 4

To test Hypotheses 3 and 4 self-efficacy was regressed on a set of orthogonally coded variables. The first variable, testing Hypothesis 3, contrasted adherents with non-adherents. The second variable, testing Hypothesis 4 , contrasted long-term adherents with recent adherents. As shown in Table 5, adherents had significantly higher levels of self-efficacy than non-adherents, and long-term adherents had significantly higher levels of self-efficacy than recent adherents $\left(R=.062, F_{(1,0)}=20.771, p=.000\right)$. These relationships held even when the social variables were included in the model. While the social variables again accounted for most of the variance in the model $\left(R^{2}=.188, F_{3,30}=49.490, p=.000\right)$, length of adherence accounted for a significant $2.9 \%$ of the 
Table 5

Mean scores on self-efficacy for contrasts comparing non-adherents with adherents (Hypothesis 3) and recent adherents with long-term adherents (Hypothesis 4)

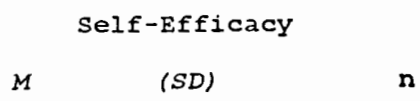

Hypothesis 4

Recent Adherent

Long-term Adherent

$b=.010 \quad t=2.90 \quad p=.004$

$\begin{array}{lll}78.4 & (14.2) & 107 \\ 83.2 & (14.3) & 347\end{array}$

347 
variance after controlling for the social variables $\left(F_{(2,593)}=11.511, p=.000\right)$.

\section{Hypothesis 5}

As seen from Table 2, cell sizes were quite small in some of the behavior type groups, most notably among those recent adherents who were either celibate or engaged in safer sexual behaviors using condoms. Because of this, celibate and masturbating behaviors were pooled into a non-penetrating sex category, and oral sex without a condom and oral or anal sex with a condom were pooled into a penetrating sex category. Psychological health was then regressed on a dummy coded variable comparing penetrators with nonpenetrators.

Only anxiety was significantly predicted by penetration (see Table 6). Those engaging in penetrating behaviors were significantly less anxious than those engaging in non-penetrating behaviors. When penetration type alone was included in the model it accounted for a significant $8.1 \%$ of the variance in the model $\left(F_{(1,100)}=8.795, p=.004\right)$. Although when the social variables were included in the model they 
Table 6

Mean scores on depression, anxiety, and subjective well-being for recent adherents, comparing penetrators with nonpenetrators (Hypothesis 5)

\begin{tabular}{|c|c|c|c|c|c|c|c|c|}
\hline \multicolumn{3}{|c|}{ Depression } & \multicolumn{3}{|c|}{ Anxiety } & \multicolumn{3}{|c|}{ Well-Being } \\
\hline M & (SD) & $n$ & $M$ & $(S D)$ & $n$ & $M$ & (SD) & $n$ \\
\hline 36.2 & $(20.9)$ & 80 & 16.3 & $(16.2)$ & 79 & 55.4 & $(23.5)$ & 80 \\
\hline 46.7 & $(29.3)$ & 23 & 29.2 & $(24.9)$ & 23 & 48.0 & $(28.5)$ & 23 \\
\hline$b=10.50$ & $t=1.93$ & $p=.057$ & $b=12.97$ & $t=2.97$ & $p=.004$ & $b=-7.42$ & $t=-1.25$ & $p=.213$ \\
\hline
\end{tabular}


accounted for most of the variance $\left(R^{2}=.152, F_{(3,92)}=\right.$ $6.019, p=.001$, the penetration variable still accounted for a significant $9.9 \%$ of the variance $\left(F_{(1,92)}\right.$ $=11.745, p=.001)$.

Penetration was not significantly related to either depression or subjective well-being, although the direction of the relationship suggests that as with anxiety, those engaging in non-penetrating behaviors are more depressed and have lower levels of subjective well-being.

\section{Hypothesis 6}

Hypothesis 6 predicted that the effects of the particular behavior type adopted would differ between long-term and recent adherents. To test this, psychological health was regressed on adherence, behavior type, and the interaction between adherence and behavior type. The interaction was only found to be significant for anxiety. Table 2 and Figure 1 show that although no difference was found between penetrators and non-penetrators among long-term adherents, among recent adherents non-penetrators were significantly more anxious than penetrators $(b=9.796$, 


\section{Figure 1}

Mean Score on Anxiety for long-term and recent adherents comparing the effects of penetration behaviors (Hypothesis 6).

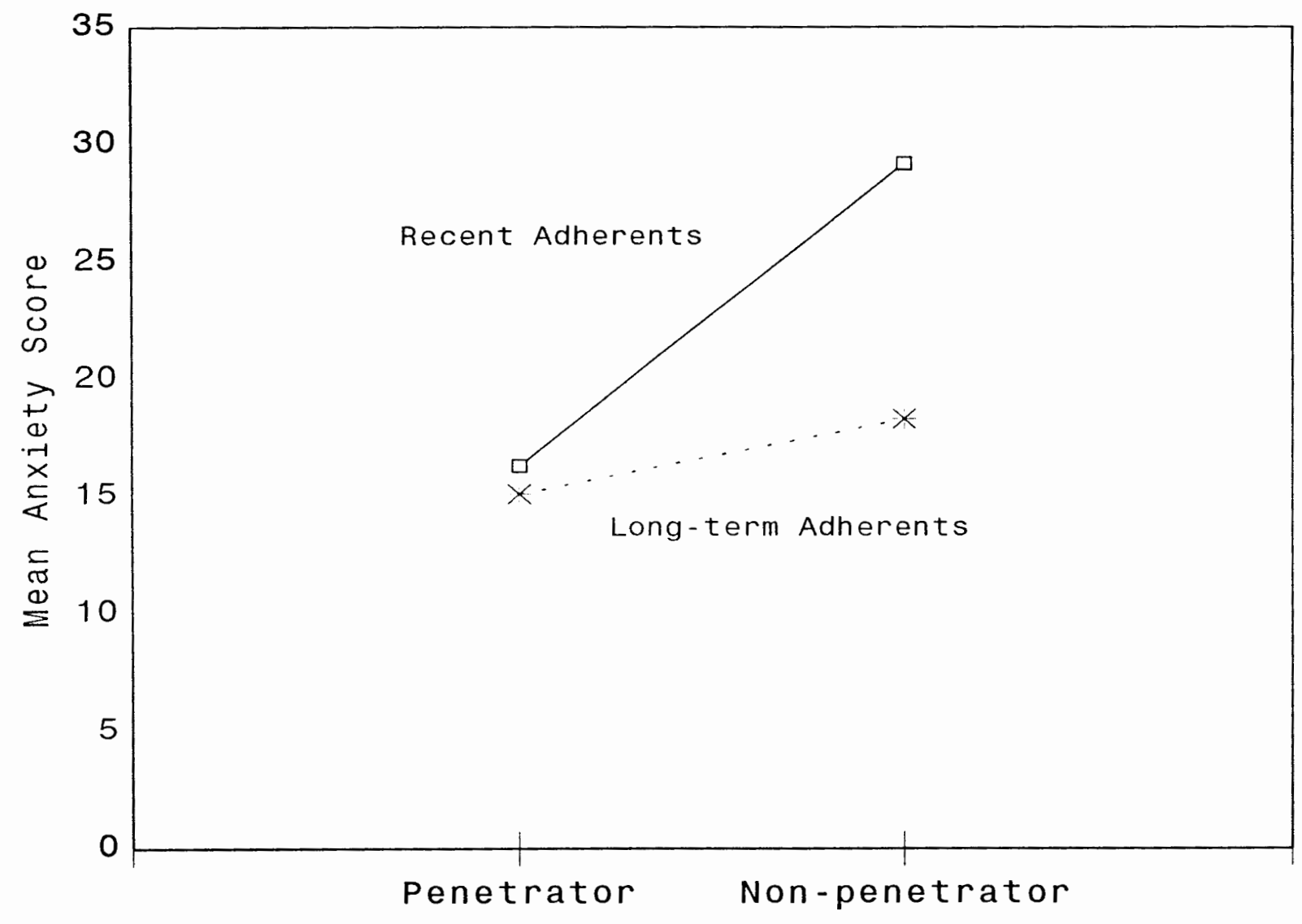


$t=2.203, p=.028$. No similar interaction effect was found for depression or subjective well-being.

\section{Discussion}

The first goal of this study was to examine the psychological consequences of behavior change so that we might better understand behavior as part of an ongoing process entailing initial behavior change, psychological consequences, and long-term behavior maintenance. The results of this study provide qualified support for the suggestion that behavior change, traditionally considered as a final outcome, is itself a factor influencing psychological outcomes and, subsequently, the maintenance of long-term behavior patterns.

\section{The Effects of Behavior Change}

Respondents who had recently changed from less safe to safer sexual behaviors had a lower sense of wellbeing than those who had continued engaging in anal sex without a condom or those who had been adhering to safer sexual behaviors for more than a year. of course, not all of the recent adherents were new 
adherents. Some may have been re-adherents who had previously adopted safer sexual behaviors, relapsed to riskier behaviors, and once again adopted safer behaviors. However, the path to adherence is not at issue here, only the recency of adherence. The finding of a psychological cost to recent adherence suggests that there will, in fact, be a pattern of adherence, relapse, and re-adherence. Were re-adherents to be excluded from the recent adherents this psychological cost might well have been missed.

It had also been anticipated that long-term adherents of safer sexual behaviors -- those who had not engaged in anal sex without a condom for longer than a year -- would report significantly better psychological health than those who were still engaging in the most risky sexual behavior. However, the fact that no difference in psychological outcomes was found between long-term and non-adherents serves further to support the hypothesis that behavior change is itself psychologically difficult. Subjective well-being decreased after recently changing from high risk to safer sexual behaviors. However, the maintenance of safer sexual behaviors was no more beneficial to a 
subjective sense of well-being than was the maintenance of high risk sexual behaviors.

Although no significant effects were found for either anxiety or depression, the direction of the effect was consistent with the hypothesis that behavior change has psychological consequences. Those who had most recently adopted safer sexual behaviors were both more depressed and more anxious than those who continued engaging in anal sex without a condom and those who had adhered to safer sexual behaviors for longer than a year. While this effect was not statistically significant, it should be recalled that the analysis was a very conservative test of this effect since recent adherents in this study may have changed their behavior as much as 11 months earlier. The longer the maintenance of safer sexual behaviors among the recent adherents, the more similar their psychological outcomes should be to the long-term adherents. The fact that there is no consistent pattern of psychological outcomes between non-adherents and long-term adherents lends additional support to the possibility that the consistency of the effects on recent adherents is real. These results suggest that 
additional studies with better discrimination of the time at which the behavior change occurred are warranted.

The Effects of Type of Behavior Change

These findings also lend support to the hypothesis that the type of behavior change adopted can influence psychological health. Those recent adherents who adopted penetrating, safer sexual behaviors were significantly less anxious than those who adopted nonpenetrating behaviors. Again, while not achieving statistical significance, the data were consistent in showing penetrators to be less depressed and to have a better sense of subjective well-being than nonpenetrators.

The significant interaction effect on anxiety between time of adherence and type of behavior lends support to the supposition that behaviors that are amenable to initial behavior change may differ from those that are conducive to long-term maintenance.

\section{Effects on Self-Efficacy}

The second goal of this study was to clarify and 
confirm the important role of self-efficacy in AIDSrelated behavior change by assessing the effect on self-efficacy of adherence to safer sexual behaviors. The study results strongly support the hypothesized role of self-efficacy in this regard. Adherents, as a whole, had a significantly better sense of selfefficacy than non-adherents. This suggests that while there may be some psychological costs to behavior change, there may also be some rewards. In addition, long-term adherents had a significantly better sense of self-efficacy than more recent adherents, suggesting that those who are consistent in adhering to safer sexual behaviors can reap increasing psychological benefits in the form of improved self-efficacy.

\section{Problems of Causality}

Because these data are cross-sectional, the causal relationships among the examined constructs are ambiguous. That ambiguity is nowhere more evident than with the data concerning self-efficacy. This ambiguity, which I think is inherent in the construct, is, paradoxically, one of the strengths of the construct of self-efficacy. Self-efficacy has 
consistently been found to be strongly predictive of later behaviors such as relapse or maintenance (McKusick, Coates, Morin, Pollack, \& Hoff, 1990; Velicer, Diclemente, Rossi, \& Prochaska, 1990; Siegel, Mesagno, Chen, \& Christ, 1989; Prochaska, Crimi, Lapsanski, Martel, \& Reid, 1982). As such it might reasonably be considered as a causal influence on behaviors. Nevertheless, self-efficacy is assessed as a measure of an individual's perceived ability to engage in specific behaviors. To the degree to which this perception is formed by actual success in engaging in those behaviors, self-efficacy might also be seen as inherently a result of previous successful behavior. The strength of the construct is that by its very nature it reflects the very intimate regenerative relationship between behavior change and psychological outcome. This strength places a heavy burden on the investigator, however, to ensure that the causal relationships are clear. Although this study suggests the possibility that behavior change and the maintenance of changed behaviors enhances selfefficacy, additional studies clarifying the causal relationship are clearly warranted. By clearly 
establishing the causal pathway from belief in one's ability to engage in specific behaviors (selfefficacy), to actual engagement in those behaviors, to enhanced self-efficacy, psychological research can suggest a systematic approach to successful behavior change. From a more theoretical perspective clarification of the causal relationships will enhance our understanding of the cyclical, regenerative nature of the construct.

The lack of causal clarity holds true as well for the relationship between psychological outcomes and type of behavioral adaptation. While it is possible that the adoption of non-penetrating behaviors results in higher levels of anxiety than the adoption of penetrating behaviors, it is also likely, possibly more so, that those respondents who were more anxious about their sexual relationships adopted the safer nonpenetrating behaviors.

The causal ambiguity is, I think, less of a problem for the relationship between time of adherence and psychological outcome. One could certainly argue that respondents who were more anxious or depressed or who had a decreased sense of subjective well-being were 
more inclined to change their behaviors than the less depressed or anxious, or better off respondents. However, the sharp decline in psychological health among those who had most recently changed, along with a return to pre-change levels for those who had successfully maintained their behaviors for more than a year, suggests that we are, in fact, seeing an effect of behavior change on psychological health. The possibility that this effect is real argues for additional, longitudinal studies to confirm the effects of behavior change on psychological outcomes and to identify whether specific types of behavior change have more or less harmful psychological effects. More importantly, studies are needed to identify those factors amenable to intervention which help to prevent the psychological costs of behavior change, or which minimize such costs until the psychological benefits of long-term adherence, such as enhanced self-efficacy, can be realized.

\section{Limitations}

The most serious limitation of the study is that the data are not longitudinal. A complete understanding of 
the process of relapse can only be gained through a longitudinal design. Finding a significant correlation between longevity of adherent behaviors and psychological outcomes does not establish a causal relationship. Nevertheless, it does suggest that such a relationship is plausible and ought to be further explored.

The study is also limited by the measure used to assess length of adherence. Although non-adherence and long-term adherence can be reliably determined, the measure of short-term adherence is somewhat problematic. All that can be reliably known about the short-term adherents is that they had not engaged in high risk sex (anal sex without a condom) in the previous thirty days, but that they had engaged in it in the previous year. However, one cannot be sure how recently they have adopted safer sexual behaviors. These behaviors may be of very recent origin (only in the past thirty days) or they may have begun as long as 11 months earlier. However, this ambiguity provided a conservative test of the effects of time of adherence on psychological health. The significant finding for subjective well-being suggests, therefore, that such a 
relationship is real. The consistency in the direction of the effects on depression and anxiety, while not significant, suggests the need for additional studies in which the length of time since adopting safer sexual behaviors is more accurately assessed.

\section{Contributions}

The results of this study offer no clear conclusions regarding the relationship between the adoption of safer sexual behaviors and psychological health. However, no clear conclusions were intended. Rather this study was intended to raise questions which would suggest that alternatives to traditional approaches towards AIDS-related behavior change should be explored.

Models such as the Health Belief Model, the Theory of Reasoned Action, the Information-MotivationBehavioral skills model and the AIDS Risk Reduction Model take a traditional approach which attempts to understand the factors affecting behavior change. Nothing in these findings is intended to suggest that these models should be discarded or replaced. Whatever their weaknesses each adds its own unique perspective 
to our complex understanding of human psychosocial behaviors. Yet as models of behavior change they cannot adequately address the factors affecting longterm behavior maintenance. Instead, each of these models, when applied in the context of AIDS-related behavior change, would consider the adoption of safer sexual behaviors as a successful outcome.

However, the findings of the current study, while not conclusive, suggest that the adoption of safer sexual behaviors should not, in and of itself, be viewed as a successful outcome. The data suggest that behavior change carries with it a price tag in psychological dollars. Those designing interventions intended to bring about successful change from highrisk to safer sexual behaviors may need to be cognizant of the costs of behavior change. However, few studies of AIDS-related behavior change have considered these costs.

I have suggested that we look to the research on habitual behaviors such as alcohol and drug use, smoking, and weight control. Models based on this research, such as the Relapse Prevention (RP) model and cycle of change models, consider behavior as part of an 
ongoing process entailing behavior change,

psychological health, and either relapse or long-term behavior maintenance. The RP model, for instance, while recognizing self-efficacy as a factor influencing the maintenance of abstinent behaviors, also recognizes that self-efficacy itself is influenced by success or failure at maintenance (Marlatt and Gordon, 1985). By drawing on this broader literature on habit change and habit formation, this study has strengthened the theoretical framework from which to approach AIDSrelated behavior change. 
References

Adib, S. M., \& Ostrow, D. G. (1991). Trends in HIV/AIDS behavioural research among homosexual and bisexual men in the United States: 1981-1991. AIDS Care, 3, 281-287.

Adib, S. M., Joseph, J. G., Ostrow, D. G., \& James, S. A. (1991). Predictors of relapse in sexual practices among homosexual men. AIDS Education and Prevention, $3,293-304$.

Ajzen, I., \& Fishbein, M. (1980). Understanding attitudes and predicting social behavior. Englewood Cliffs, N.J.: Prentice-Hall, Inc.

Andrews, F. M., \& Withey, S. B. (1976). Social indicators of well-being. New York: Plenum. Aspinwall, L. G., Kemeny, M. E., Taylor, S. E., Schneider, S. G., \& Dudley, J. P. (1991) . Psychosocial predictors of gay men's AIDS riskreduction behavior. Health Psychology, 10, 432-444. Bandura, A. (1977). Social learning theory. Englewood Cliffs, NJ: Prentice-Hall, Inc.

Bandura, A. (1986). The explanatory and predictive scope of self-efficacy theory. Journal of Social and 
Clinical Psychology, 4, 359-373.

Becker, M. H. (1974). The Health Belief Model and personal health behavior. Health Education Monographs, 2, 324-508.

Becker, M. H., \& Joseph, J. G. (1988). AIDS and

behavioral change to reduce risk. American Journal of Public Health, 78, 394-410.

Brickman, P., Rabinowitz, V. C., Karuza, J., Coates,

D., Cohn, E., \& Kidder, L. (1982). Models of helping and coping. American Psychologist, 37, 364-384. Brownell, K. D., Glynn, T. J., Glasgow, R., Lando, H., Rand, C., Gottlieb, A., \& Pinney, J. M. (1986). Interventions to prevent relapse. Health Psychology, $5, \quad 53-68$

Catania, J. A., Coates, T. J., Stall, R., Bye, L., Kegeles, S. M., Capell, F., Henne, J., McKusick, L., Morin, S., Turner, H., \& Pollack, L. (1991). Changes in condom use among homosexual men in San Francisco. Health Psychology, 10, 190-199.

Catania, J. A., Kegeles, S. M., \& Coates, T. J. (1990). Towards an understanding of risk behavior: An AIDS Risk Reduction Model (ARRM). Health Education Quarterly, 17, 53-72. 
Centers for Disease Control and Prevention (1994). HIV/AIDS Surveillance Report, March 1994. Derogatis, L. R., Lipman, R. S., Rickels, K., Uhlenhuth, E. H., \& Covi, L. (1974). The Hopkins Symptom Checklist (HSCL): A self-report symptom inventory. Behavioral Science, 19, 1-15.

Diclemente, C. C. (1986). Self-efficacy and the addictive behaviors. Journal of social and clinical Psychology, 4, 302-315.

Ekstrand, M. L., \& Coates, T. J. (1990). Maintenance of safer sexual behaviors and predictors of risky sex: The San Francisco Men's Health Study. American Journal of Public Health, 80, 973-977. Fishbein, M., \& Ajzen, I. (1975). Belief, attitude, intention and behavior: An introduction to theory and research. Reading, Mass.: Addison-Wesley. Fishbein, M. (1990). AIDS and behavior change: An analysis based on the Theory of Reasoned Action. Interamerican Journal of Psychology, 24, 37-56. Fisher, J. D., \& Fisher, W. A. (1992). Changing AIDS-risk behavior. Psychological Bulletin, 111, $455-474$

Grilo, C. M., Shiffman, S., \& Wing, R. R. (1989). 
Relapse crises and coping among dieters. Journal of Consulting and Clinical Psychology, 57, 488-495.

Hall, S. M., Havasy, B. E., \& Wasserman, D. A. (1991). Effects of commitment to abstinence, positive moods, stress, and coping on relapse to cocaine use. Journal of Consulting and clinical Psychology, $59(4), 526-532$.

Janz, N. K. \& Becker, M. H. (1984). The Health Belief Model: A decade later. Health Education Quarterly, $11,1-47$.

Joseph, J. G., Caumartin, S. M., Tal, M., Kirscht, J. P., Kessler, R. C., Ostrow, D. G., \& Wortman, C. B. (1990). Psychological functioning in a cohort of gay men at risk for AIDS: A three-year descriptive study. The Journal of Nervous and Mental Disease, $178,607-615$.

Joseph, J. G., Emmons, C. A., Kessler, R. C., Wortman, C. B., O'Brien, K., Hocker, W. T., \& Schaefer, C. (1984). Coping with the threat of AIDS: An approach to psychosocial assessment. American Psychologist, $39, \quad 1297-1302$.

Joseph, J. G., Kessler, R. C., Wortman, C. B., Kirscht, J. P., Tal, M., Caumartin, S., Eshleman, S., \& 
Eller, M. (1989). Are there psychological costs associated with changes in behavior to reduce AIDS risk? In V. M. Mays, G. W. Albee, \& S. F. Schneider (Eds.), Primary prevention of AIDS: Psychological approaches (pp. 209-224). Newbury Park, CA: SAGE Publications.

Kaemingk, K. L., \& Bootzin, R. R. (1990). Behavior change strategies for increasing condom use. Evaluation and Program Planning, 13, 47-54.

Kelly, J.A., \& Murphy, D. A. (1992). Psychological interventions with AIDS and HIV: Prevention and treatment. Journal of Consulting and Clinical Psychology, 60, 576-585.

Kelly, J. A., \& St. Lawrence, J. S. (1990). The impact of community-based groups to help persons reduce HIV infection risk behaviours. AIDS Care, 2, 25-36. Kelly, J. A., St. Lawrence, J. S., \& Brasfield, T. L. (1991). Predictors of vulnerability to AIDS risk behavior relapse. Journal of Consulting and clinical Psychology, 59, 163-166.

Kessler, R. C., O'Brien, K., Joseph, J. G., Ostrow, D. G., Phair, J. P., Chmiel, J. S., Wortman, C. B., \& Emmons, C. A. (1988). Effects of HIV infection, 
perceived health and clinical status on a cohort at risk for AIDS. Social Science and Medicine, 27, 569-578.

Marlatt, G. A., \& Gordon, J. R. (Eds.). (1985). Relapse prevention: Maintenance strategies in the treatment of addictive behaviors. New York: The Guilford Press.

Marlatt, G. A. (1985). Relapse prevention: Theoretical rationale and overview of the model. In G.A. Marlatt \& J. R. Gordon (Eds.), Relapse prevention: Maintenance strategies in the treatment of addictive behaviors (pp. 3-70). New York: The Guilford Press. Martin, J. L. (1987). The impact of AIDS on gay male sexual behavior patterns in New York City. American Journal of Public Health, 77, 578-581.

Martin, J. L., Dean, L., Garcia, M., \& Hall, W. (1989). The impact of AIDS on a gay community: changes in sexual behavior, substance use, and mental health. American Journal of Community Psychology, 17, $269-293$

Mckusick, L., Coates, T. J., Morin, S. F., Pollack, L., \& Hoff, C. (1990). Longitudinal predictors of reductions in unprotected anal intercourse among gay 
men in San Francisco: The AIDS Behavioral Research Project. American Journal of Public Health, 80, $978-983$

Montgomery, S. B., Joseph, J. G., Becker, M. H., Ostrow, D. G., Kessler, R. C., \& Kirscht, J. P. (1989). The Health Belief Model in understanding compliance with preventive recommendations for AIDS: How useful? AIDS Education and Prevention, 1, $303-323$

O'Brien, C. J. K. (1988). Primary relationships and mental health in a cohort at risk for AIDS. Dissertation Abstracts International, 48, 3156B. (University Microfilm No. DA8729290)

O'Brien, K. (1992). Social relationships and HIV prevention: The Portland Men's Study. Proceedings of the 72nd annual meeting of the Western Psychological Association (1992), 264.

O'Leary, A. (1985). Self-efficacy and health. Behavior Research Therapy, 23, 437-451.

Pedhazur, E. J. (1982). Multiple regression in behavioral research: Explanation and prediction (2nd ed.). New York: Holt, Rinehart and Winston. Peele, S. (1985). The meaning of addiction. Lexington, 
MA: Lexington Books.

Prochaska, J. O., Crimi, P., Lapsanski, D., Martel, L.,

\& Reid, P. (1982). Self-change processes,

self-efficacy and self-concept in relapse and

maintenance of cessation of smoking. Psychological

Reports, 51, 983-990.

Radloff, L. S. (1977). The CES-D Scale: A self-report

depression scale for research in the general

population. Applied Psychological Measurement, 1, 385 .

Rollnick, S., \& Heather, N. (1982). The application of Bandura's self-efficacy theory to abstinenceoriented alcoholism treatment. Addictive Behaviors, $7,243-250$

Salt, H., Boyle, M., \& Ives, J. (1990). HIV prevention: Current health promoting behaviour models for understanding psychosocial determinants of condom use. AIDS Care, 2, 69-75.

Siegel, K., Mesagno, F. P., Chen, J. Y., \& Christ, G. (1989). Factors distinguishing homosexual males practicing risky and safer sex. Social science and Medicine, 28, 561-569.

Stall, R. D., Coates, T. J., \& Hoff, C. (1988). 
Behavioral risk reduction for HIV infection among gay and bisexual men: A comparison of published results from the United States. American Psychologist, 43, 859-864.

sternberg, B. (1985). Relapse in weight control:

Definitions, processes and prevention strategies. In G. A. Marlatt \& J. R. Gordon (Eds.), Relapse prevention: Maintenance strategies in the treatment of addictive behaviors (pp. 521-545). New York: Guilford.

Velicer, W. F., Diclemente, C. C., Rossi, J. S., \& Prochaska, J. O. (1990). Relapse situations and self-efficacy: An integrative model. Addictive Behaviors, 15, 271-283.

Veroff, J., Douvan, E., \& Kulka, R. A. (1981). The inner American. New York: Basic Books. Yates, A. J., \& Thain, J. (1985). Self-efficacy as a predictor of relapse following voluntary cessation of smoking. Addictive Behaviors, 10, 291-298. 


\section{Appendix}

Appendix A.

For some scale items below response categories were reversed before scales were formed so that all items were reflective of the same response direction. Items which were reversed are indicated with an asterisk preceding the wording of the item.

Independent Variables: sexual behavior and adherence longevity.

Safer sexual behaviors category. Safer sexual behavior was coded from a four-category variable operationalized as follows:

1: Celibates -- No sexual activity in previous 30 days.

2: Masturbators -- Masturbation (with or without a primary partner) but no oral or anal sex in previous 30 days.

3: Anal or oral sex with condom -- anal or oral sex with condom, but no unprotected sex in previous 30 days.

4: Oral sex without a condom -- oral sex without a 
condom, but no anal sex without a condom in previous 30 days.

Because of small cell sizes these categories were collapsed into two groups, penetrators and nonpenetrators, as follows:

1: Penetrators -- categories 3 and 4.

2: Non-penetrators -- categories 1 and 2 .

Adherence. Adherence was orthogonally coded from a three-category variable with values non-adherent, short-term adherent, and long-term adherent.

Respondents were classified into one of the three categories as follows.

1: Non-adherent -- Engaged in unprotected anal sex in previous 30 days.

2: Short-term adherent -- Engaged in unprotected anal sex in previous year but not in last 30 days.

3: Long-term adherent -- Had not engaged in unprotected anal sex in previous year. 
control variables: social support, social conflict, and social influence.

social support. A 12 item scale for respondents who were in a primary relationship with another man, and a 6 item scale for respondents who were not in a primary relationship with a man. The two sets of six items were the same except for the reference to a partner or friends. These items were previously presented by O'Brien, 1992.

Items asked of men who were not in primary

relationships:

1. My friends have given me information about AIDS that I needed to know.

2. If I had needed some practical help concerning AIDS (for instance, a ride to a doctor's), I could have relied on my friends for help

3. If I had needed to, I could have turned to my friends for guidance with some questions concerning AIDS.

4. My friends understood my feelings about AIDS. 5. My friends wanted me to follow the safer sex guidelines because they care about me.

6. If I had gotten sick and I was worried about HIV 
infection, my friends would help me.

\section{Response categories}

1: Strongly Agree

2: Somewhat Agree

3: Somewhat Disagree

4: Strongly Disagree

Further items asked of men in primary relationships (with same response categories):

7. My partner has given me information about AIDS that I needed to know.

8. If I had needed some practical help concerning AIDS (for instance, a ride to a doctor's), I could have relied on my partner for help

9. If I had needed to, I could have turned to my partner for guidance with some questions concerning AIDS.

10. My partner understood my feelings about AIDS.

11. My partner wanted me to follow the safer sex guidelines because he cares about me.

12. If I had gotten sick and I was worried about HIV infection, my partner would help me. 
Social conflict. A four item scale for respondents who were in a primary relationship with another man, and a two item scale for respondents who were not in a primary relationship with a man. The two sets of two items were the same except for the reference to a partner or someone in my personal life. These items were previously presented by O'Brien, 1992. Items asked of men who were not in primary relationships:

1. I felt tense from arguing or disagreeing with someone in my personal life about something to do with AIDS

2. Someone in my personal life really got on my nerves about something to do with AIDS.

\section{Response categories}

1: Strongly Agree

2: Somewhat Agree

3: Somewhat Disagree

4: Strongly Disagree

Further items asked of men in primary relationships (with same response categories): 
3. I felt tense from arguing or disagreeing with my partner about something to do with AIDS

4. My partner really got on my nerves about something to do with AIDS.

social Influence. An eight item scale for respondents who were in a primary relationship with another man, and a four item scale for respondents who were not in a primary relationship with a man. The two sets of four items were the same except for the reference to a partner or friends. These items were previously presented by O'Brien, 1992.

Items asked of men who were not in primary

relationships:

1. My friends have thought safer sex is a hassle.

2. My friends have thought safer sex is sexy.

3. My friends have encouraged me to practice safer sex.

4. My friends have thought it's silly to use condoms.

\section{Response categories}

1: Strongly Agree

2: Somewhat Agree 
3: Somewhat Disagree

4: Strongly Disagree

Further items asked of men in primary relationships

(with same response categories):

5. My partner has thought safer sex is a hassle.

6. My partner has thought safer sex is sexy.

7. My partner has encouraged me to practice safer sex.

8. My partner has thought it's silly to use condoms. 
Dependent variables: psychological outcomes --

depression, anxiety, subjective well-being, and selfefficacy.

Depression. These items were selected from the center for Epidemiologic Studies-Depression scale (CES-D;

Radloff, 1977)

\section{Items}

In the past month...

1. I felt depressed.

2. I felt everything I did was an effort.

3. * I felt hopeful about the future.

4. My sleep was restless.

5. I felt sad.

Response categories

1: Rarely or none of the time

2: Some or a little of the time

3: Occasionally or a moderate amount of the time

4: Most of the time 
Anxiety. These items constituted the anxiety subscale of the Hopkins Symptom Checklist (SCL-58; Derogatis et al., 1974).

Subjective well-Being. These items were adapted by O'Brien (1988) from Veroff, Douvan, \& Kulka (1981) and included a measure of global life satisfaction adapted from Andrews and Withey (1976).

\section{Items}

1. In the past month I felt satisfied with my life as a whole.

\section{Response categories}

1: Rarely or none of the time

2: Some or a little of the time

3: Occasionally or a moderate amount of the time

4: Most of the time

In the past month how satisfying have you found each of the following activities?

2. Your leisure time? 
3. Your work in and around the home?

4. Your work on the job?

5. Your sexual relationships?

6. Your friendships?

Response categories

1: Not at all satisfying

2: Somewhat satisfying

3: Satisfying

7. * Taking all things together, how would you say things are these days--would you say you're very happy, pretty happy, or not too happy these days?

\section{Response categories}

$$
\begin{array}{ll}
\text { 1: } & \text { Very happy } \\
\text { 2: } & \text { Pretty happy } \\
\text { 3: } & \text { Not too happy }
\end{array}
$$

In developing the subjective Well-Being scale, items 26 above were first scaled and weighted as if one item. Then items (1), (2-6), and (7) were weighted as a three-item scale. 


\section{Self-Efficacy}

These items were previously presented by O'Brien, 1992 .

\section{Items}

1. * If I want to have safer sex, the way I tell my partner is I talk to him about it.

2. * I can find sexy ways to be safe with a sexual partner.

3. * I would feel comfortable talking about safer sex with a potential sex partner.

4. * I find it easy to work out an agreement about safer sex with a potential sex partner.

5. * I would be able to leave a sexual relationship if my partner would not agree to safer sex.

\section{Response categories}

1: Strongly Agree

2: Somewhat Agree

3: Somewhat Disagree

4: Strongly Disagree 